\title{
PERFIL EPIDEMIOLÓGICO DAS INTERNAÇÕES POR NEOPLASIAS MALIGNAS DA PRÓSTATA NO CEARÁ EM 2017
}

\author{
Filipe Rolim Medeiros ${ }^{l}$, Maria Mirelle Ferreira Leite Barbosa ${ }^{l}$, Daniela Matos Carneiro ${ }^{l}$, \\ Inêz Gabrielle Duarte Sousa ${ }^{l}$, Francisco Davi Gomes Araújo ${ }^{l}$, Flaviana Ferreira de Oliveira ${ }^{1}$, \\ Millene Ivania Ferreira Leite Barbosa ${ }^{2}$
}

Introdução: O câncer de próstata é o quinto tumor maligno mais frequente no mundo. As taxas de incidência e de mortalidade por câncer de próstata variam grandemente entre os diferentes países, possivelmente em decorrência de fatores ambientais e das variações na probabilidade de eventos genéticos necessários para a progressão do tumor. O elevado número de internamentos por neoplasias malignas da próstata sugere ser reflexo da maior expectativa de vida da população masculina. No Brasil, a incidência dessa afecção tem aumentado consideravelmente. Sem considerar os tumores de pele não melanoma, o câncer prostático é o mais frequente em todas as regiões. Objetivo: Caracterizar o perfil epidemiológico das internações dos pacientes com neoplasia maligna da próstata no Ceará durante o ano de 2017. Método: Trata-se de um estudo descritivo e analítico, de caráter retrospectivo, baseado em dados secundários do Departamento de Informática do SUS (DATASUS). Entre janeiro e dezembro de 2017, foi contabilizado o número de internamentos por neoplasia maligna da próstata no Ceará, analisando a prevalência entre regiões macrorregiões de saúde assim como as variáveis raça/cor, faixa etária, caráter dos atendimentos e estabelecimento. Resultados: O Ceará apresentou um total de 1023 internamentos registrados por câncer de próstata no ano de 2017. Em relação às macrorregiões de saúde, há um predomínio do número de internamentos realizados em Fortaleza (82,01\%), seguido por Sobral (8,60\%), Cariri (7,42\%), Litoral Leste $(1,27 \%)$ e, por fim, Sertão Central (0,68\%). Quanto à raça/cor, mais de $75 \%$ das vítimas são pardas entre 60 a 69 anos (40,17\%). Analisando o estabelecimento de internação, o Instituto do Câncer do Ceará teve o maior índice $(44,09 \%)$, seguido pelo Hospital Cura DARS $(21,13 \%)$ e pela Santa Casa de Misericórdia de Fortaleza (17,80\%). Das internações realizadas, 71,70\% foram eletivas e 28,30\% em caráter de urgência. Conclusão: Foi possível observar no estudo realizado que o Ceará acompanha a alta taxa de prevalência do país. O principal perfil epidemiológico das vítimas, corroborando com a literatura, foi idoso, pardo, principalmente das regiões litorâneas do Ceará. Logo, esses indivíduos merecem investimento da sociedade para que as internações e complicações da neoplasia sejam minimizadas.

Palavras-chaves: Próstata; Neoplasia de Próstata; Ceará.

\footnotetext{
${ }^{1}$ Acadêmico de Medicina em Faculdade de Medicina Estácio de Juazeiro do Norte - ESTÁCIO FMJ;

${ }^{2}$ Cirurgiã Geral formada pelo Hospital Getúlio Vargas - HGV - Recife (PE);

Autor correspondente: filipe_rm89@hotmail.com.
}

18 Id on Line Rev. Mult. Psic. V.12, N. 40. 2018 - ISSN 1981-1179 EDIÇÃO ESPECIAL: I CURSO DE ONCOLOGIA DO CARIRI / II JORNADA DE PESQUISA QUANTI-QUALITATIVA EM ONCOLOGIA. JUAZEIRO DO NORTE, 05 A 10 DE MARÇO DE 2018. Edição eletrônica em http://idonline.emnuvens.com.br/id 